Volume 3, Issue 1, pages 111-124

\title{
Obtaining the Efficiency and Effectiveness of Fin in Unsteady State Conditions Using Explicit Finite Difference Method
}

\author{
Petrus Kanisius Purwadi $^{1, *}$, Budi Setyahandana ${ }^{1}$, R.B.P. Harsilo ${ }^{1}$ \\ ${ }^{1}$ Department of Mechanical Engineering, Faculty of Science and \\ Technology, Sanata Dharma University, Yogyakarta, Indonesia \\ *Corresponding Author: pkpurwadi1966@gmail.com
}

(Received 10-04-2021; Revised 10-05-2021; Accepted 17-05-2021)

\begin{abstract}
This paper discusses the search for fin efficiency and effectiveness in unsteady state conditions using numerical computation methods. The straight fin under review has a cross-sectional area that changes with the position $\mathrm{x}$. The cross section of the fin is rectangular. The fins are composed of two different metal materials. The computation method used is the explicit finite difference methods. The properties of the fin material are assumed to be fixed, or do not change with changes in temperature. When the stability requirements are met, the use of the explicit finite difference methods yields satisfactory results. The use of the explicit finite difference methods can be developed for various other fin shapes, which are composed of two or more different materials, time-varying convection heat transfer coefficient, and the properties of the fin material that change with temperature.
\end{abstract}

Keywords: fin, efficiency, effectiveness, finite-difference, unsteady state 


\section{International Journal of Applied Sciences and Smart Technologies}

Volume 3, Issue 1, pages 111-124

p-ISSN 2655-8564, e-ISSN 2685-9432

\section{Introduction}

In the design of fins, the important thing to know is the efficiency and effectiveness of the fins. There are many ways to know the value of fin efficiency and fin effectiveness. For certain fin shapes, the value of the efficiency and effectiveness of the fins can be found by using existing charts. For fins that do not yet exist, other ways are needed to get them. For cases in unstable state, the solution becomes more complicated. One way that can be done is by using numerical computation methods.

Several articles [1-7] related to the efficiency and fin effectiveness of fins in the unsteady state have helped in in solving this problem. In this case, the case discussed is a fin which is composed of two different materials and is in an unsteady state. The shape and cross-section of the fins are different from those that have been used as the object of the previous discussion. In this case, the cross-sectional area of the fin changes with the change in position $\mathrm{x}$. The shape of the fin chosen is a truncated rectangular pyramid. Figure 1 presents an image of the fin shape to be discussed. With the total length of the fin $L$, where $L=L_{1}+L_{2}$ and $L_{1}=L_{2}$
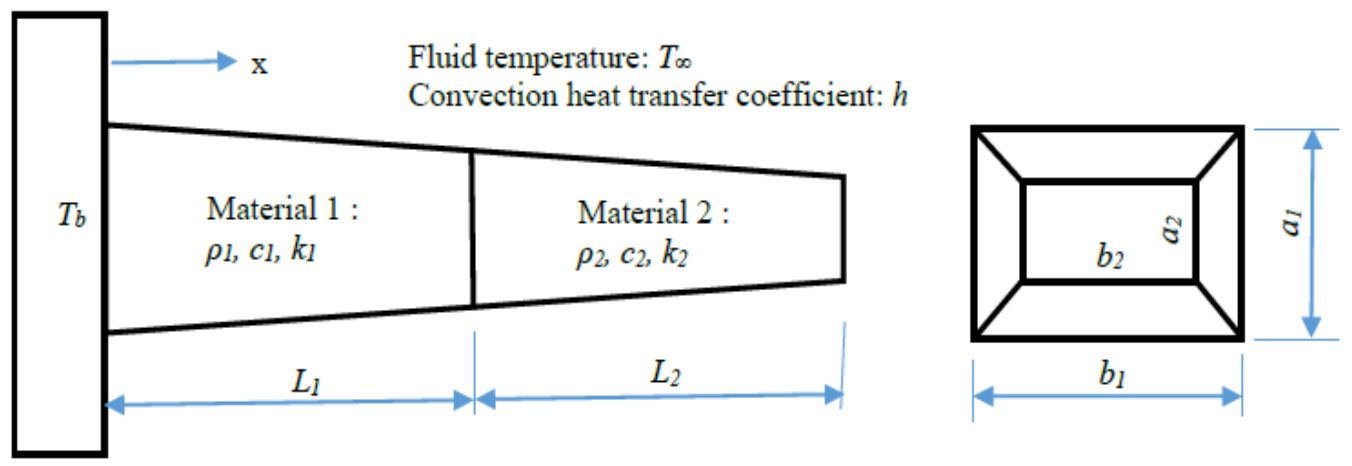

Figure 1. Straight fin with a truncated rectangular pyramid shape

The mathematical model for this problem is expressed by equation (1):

$$
\begin{gathered}
\frac{\partial^{2} T(x, t)}{\partial x^{2}}+\frac{h P}{k A_{p}}\left(T(x, t)-T_{\infty}\right)=\frac{1}{\alpha} \frac{\partial T(x, t)}{\partial t} \quad 0<x<L, x \neq L_{1}, t>0 \\
\alpha=\frac{k}{\rho c}
\end{gathered}
$$

with initial condition: 


\section{International Journal of Applied Sciences and Smart Technologies}

Volume 3, Issue 1, pages 111-124

p-ISSN 2655-8564, e-ISSN 2685-9432

$$
T(x, 0)=T_{i}=T_{b} \quad 0 \leq x \leq L, t=0
$$

and boundary condition:

$$
\begin{array}{cc}
T(0, t)=T_{b} & x=0, t>0 \\
k_{2} \frac{\partial T(x, t)}{\partial x}=h \frac{A s}{A p_{1}}\left(T(x, t)-T_{\infty}\right) & x=L, t>0 \\
k_{1} \frac{\partial T(x, t)}{\partial x}=k_{2} \frac{A p_{2}}{A_{p 1}} \frac{\partial T(x, t)}{\partial x}+h A_{s} \frac{A s}{A p_{1}}\left(T_{\infty}-T(x, t)\right) & x=L_{1}, t>0
\end{array}
$$

In equations (1)-(6) we have used the notations:

$x \quad: \quad$ Stated the position on fin, $\mathrm{m}$

$t \quad:$ Stated the time, seconds

$T(x, t) \quad$ : Temperature at the $\mathrm{x}$ position, at the $\mathrm{t}$ time, ${ }^{\circ} \mathrm{C}$

$T_{\infty} \quad: \quad$ Fluid temperature, ${ }^{\circ} \mathrm{C}$.

$T_{i} \quad$ : Initial temperature of the fin, ${ }^{\circ} \mathrm{C}$

$T_{b} \quad: \quad$ Temperature at the base of the fin, ${ }^{\circ} \mathrm{C}$

$L_{1} \quad$ : The length of the fin with material lor the length of the fin with material $1, \mathrm{~m}$

$L_{2} \quad$ : The length of the fin with material 1or the length of the fin with material $2, \mathrm{~m}$

$L \quad$ : The length of the fin, $L=L_{1}+L_{2}, \mathrm{~m}$

$A_{p} \quad: \quad$ Cross-sectional of the fin, $\mathrm{m}^{2}$

$P \quad: \quad$ Around the cross section, $\mathrm{m}$

$k \quad: \quad$ Conduction heat transfer coefficient of fin material 1 or material $2, \mathrm{~W} /\left(\mathrm{m} .{ }^{\circ} \mathrm{C}\right)$

$k_{1} \quad: \quad$ Conduction heat transfer coefficient of fin material $1, \mathrm{~W} /\left(\mathrm{m} .{ }^{\circ} \mathrm{C}\right)$

$k_{2} \quad: \quad$ Conduction heat transfer coefficient of fin material $2, \mathrm{~W} /\left(\mathrm{m} .{ }^{\circ} \mathrm{C}\right)$

$h \quad: \quad$ Convection heat transfer coefficient, $\mathrm{W} /\left(\mathrm{m}^{2}{ }^{\circ} \mathrm{C}\right)$

$\rho \quad: \quad$ Density of the material, $\mathrm{kg} / \mathrm{m}^{3}$

$c \quad: \quad$ Specific heat of the material, $\mathrm{kJ} /\left(\mathrm{kg} .{ }^{\circ} \mathrm{C}\right)$

$c_{1} \quad: \quad$ Specific heat of the material $1, \mathrm{~J} /\left(\mathrm{kg} .{ }^{\circ} \mathrm{C}\right)$

$c_{2} \quad: \quad$ Specific heat of the material $2, \mathrm{~J} /\left(\mathrm{kg} .{ }^{\circ} \mathrm{C}\right)$

$\alpha \quad:$ Thermal diffusivity of the material, $\mathrm{m}^{2} / \mathrm{s}$

\subsection{Calculation Steps}

The steps used to calculate the efficiency and effectiveness of the fin in an unsteady state condition using the numerical method are as follows:

1. Determine fixed variable variables, such as: $h, \rho_{1}, \rho_{2}, c_{1}, c_{2}, k_{1}, k_{2}, a_{1}, b_{1}$ $a_{2}, b_{2}, T_{\infty}, T_{i}, T_{b}, L_{1}, L_{2}, L, P, A s_{i}, A p_{i}, m, \Delta x, \Delta t$. 


\section{International Journal of Applied Sciences and Smart Technologies}

Volume 3, Issue 1, pages 111-124

p-ISSN 2655-8564, e-ISSN 2685-9432

2. Perform temperature calculations for each control volume from time to time from volume control 1 to control up to volume control to $\mathrm{m}$. Volume control 1 is on the bottom of the fin and volume control $\mathrm{m}$ is on the end of the fin. The total volume of the control is $\mathrm{m}$.

3. Calculate the actual heat flow rate $\left(q_{a c t}\right)$ released by the fins, the ideal heat flow rate released by the fins $\left(q_{\text {ideal }}\right)$, and the heat flow rate released if there are no fins $\left(q_{\text {no,fin }}\right)$. Temperature calculations are carried out from time to time.

4. Perform calculations of fin efficiency $(\eta)$ from time to time

5. Perform calculations of fin effectiveness $(\epsilon)$ from time to time

Figure 2 presents a flow chart to get the efficiency and effectiveness of the fins.

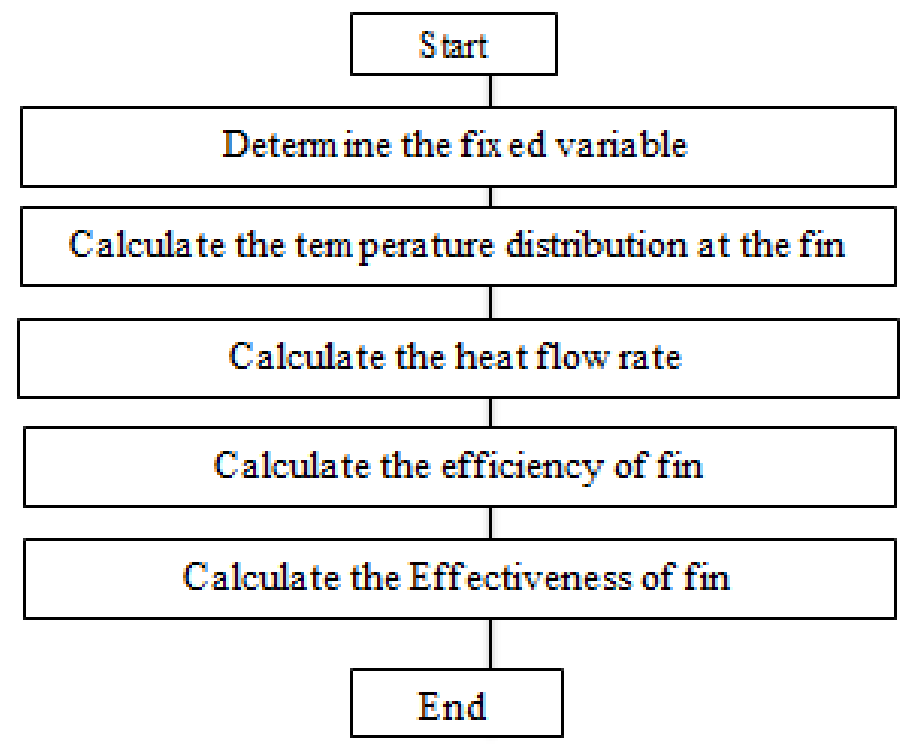

Figure 2. Flow chart to get the efficiency and effectiveness of the fins

Some of the assumptions used in this calculation are:

1. The fluid temperature and the convection heat transfer coefficient are uniform and constant.

2. Material properties (density, specific heat, thermal conductivity of the material) are uniform and constant.

3. The shape of the fins is fixed and does not change in volume during the process. 


\section{International Journal of Applied Sciences and Smart Technologies}

Volume 3, Issue 1, pages 111-124

p-ISSN 2655-8564, e-ISSN 2685-9432

4. The transfer of heat by radiation is negligible.

5. The connection on the two fin materials is assumed to be perfectly connected.

6. No energy generated in the fins.

7. The heat transfer by conduction in the fins is assumed to take place in only one direction, the $\mathrm{x}$ direction.

8. The entire surface of the fins is in contact with the fluid around the fins.

\subsection{Control volume and energy balance on the control volume}

Figure 3 shows a fin image divided into many controls. The total control volume is $\mathrm{m}$. Volume control 1 is at the base of the fin, and volume control $m$ is at the end of the fin. The volume control $p$ is located at the border of the two fin materials. In the control volume $p$, the half control volume is made of material 1 , and the half control volume is made of material 2. The numbering of the control volume starts from the bottom of the fin to the end of the fin in sequence, with the names of the volume controls $1,2,3, \ldots, m$. The distance between control volumes is $\Delta x$. At the control volume $i=1,2,3, \ldots, m-$ 1 , the control volume performs a convection heat transfer process through its blanket surface. At the control volume $m$, the process of convection heat transfer outside the blanket surface, also carries out the process of convection heat transfer through the cross-sectional area of the fins. The thickness of the volume control at the base of the fin and at the tip of the fin is $0,5 \Delta x$. The control volume thickness of $i=$ $1,2,3, \ldots, m-1$ is $\Delta x$.

In Figure 4, Figure 5 and Figure 6, the convection heat flow is represented by $q_{c}$. The conduction heat flow from the control volume in position $i-1$ to the control volume at $i$, is represented by $q_{i-1}$. The conduction heat flow from the control volume in position $i+1$ to the control volume in position $i$, expressed as $q_{i+1}$. 
Volume 3, Issue 1, pages 111-124

p-ISSN 2655-8564, e-ISSN 2685-9432
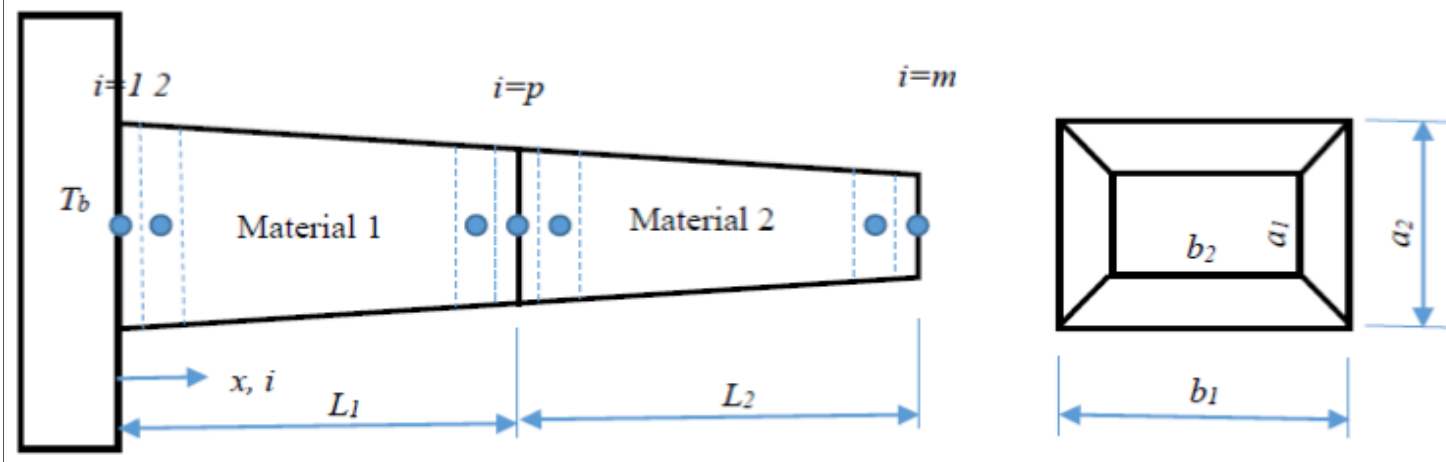

Figure 3. Distribution of volume control on the fins

The energy balance of the control volume on the fins, without energy generation, in the unsteady state condition can be stated by the following statement:

$$
\left[\begin{array}{c}
\text { all energy entering } \\
\text { the control volume during } \\
\text { the time interval } \Delta \mathrm{t}
\end{array}\right]=\left[\begin{array}{c}
\text { the energy change } \\
\text { in the control volume } \\
\text { during in the time interval } \Delta \mathrm{t}
\end{array}\right]
$$

It can also be expressed by equation (7):

$$
\sum_{i=1}^{i=k} q_{i}=\rho c V \frac{\Delta T}{\Delta t}
$$

Figure 4 presents the energy balance at the control volume inside the fin body, or at the control volume at position $i=2,3,4, \ldots, p-3, p-2, p-1$ (between the base of the fin with the border of the two fin materials) and in position $i=p+1, p+2, p+$ $3, \ldots, m-2, m-1$ (between the border of the two fin materials with the tip of the fin). The energy balance in this control volume can be expressed by equation (8):

$$
q_{i-1}+q_{i+1}+q_{c}=\rho c V \frac{T_{i}^{n+1}-T_{i}^{n}}{\Delta t} .
$$


Volume 3, Issue 1, pages 111-124

p-ISSN 2655-8564, e-ISSN 2685-9432

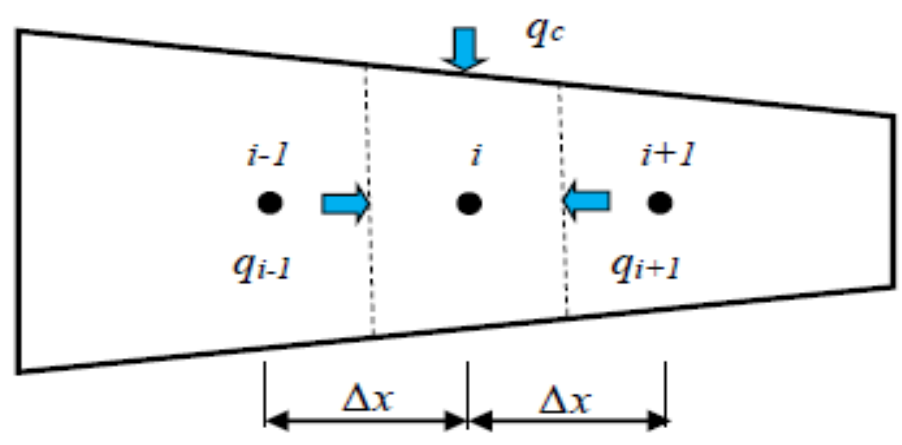

Figure 4. The energy balance at the control volume at $i=2,3,4, \ldots, p-2, p-1$ and at the control volume at $i=p+1, p+2, p+3, \ldots, m-2, m-1$

In equations (8)-(10), $T_{i}^{n}$ is the temperature in control volume $i$ at time $t=n$ or at time $t$, and $T_{i}^{n+1}$ is at control volume $i$ at time $t=n+1$ or when $t=t+\Delta t$. Assume that the control volume has a uniform temperature. The variable $V$ represents the volume, $\Delta t$ and represents the time interval.

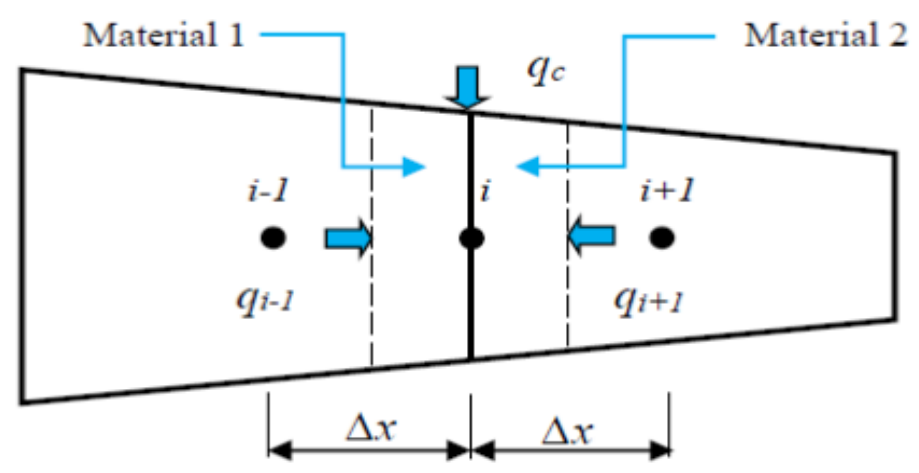

Figure 5. Energy balance on volume control at $i=p$ 


\section{International Journal of Applied Sciences and Smart Technologies}

Volume 3, Issue 1, pages 111-124

p-ISSN 2655-8564, e-ISSN 2685-9432

Figure 5 presents the energy balance at the control volume at the boundary of the two materials or at $i=p$. At the control volume at $i=p$, the control volume is composed of two different materials. The thickness of the control volume for material 1 is $0.5 \Delta x$, the thickness of the control volume for material 2 is $0.5 \Delta x$. The energy balance at the control volume in position $i=p$ can be expressed by equation (9):

$$
q_{i-1}+q_{i+1}+q_{c}=\rho_{1} c_{1} V_{i} \cdot \frac{T_{i}^{n+1}-T_{i}^{n}}{\Delta t}+\rho_{2} c_{2} V_{2} \frac{T_{i}^{n+1}-T_{i}^{n}}{\Delta t}
$$

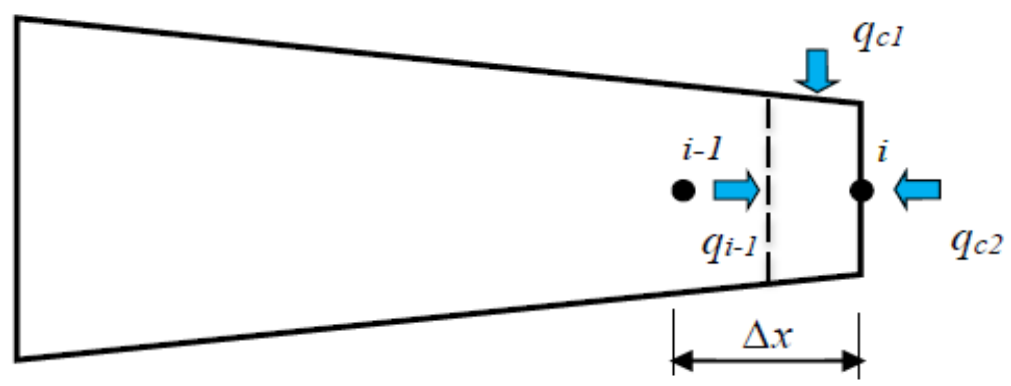

Figure 6. Energy balance on the control volume di $i=m$

Figure 6 presents the energy balance at the control volume at the tip of the fin or at $i=m$. In the control volume at the fin tip, the process of convection heat transfer through the blanket surface and the cross-sectional surface of the fin tip. The thickness of the volume control at the tip of the fin is $0.5 \Delta x$. The energy balance at the control volume at position $i=m$ can be expressed by equation (10):

$$
q_{i-1}+q_{c 1}+q_{c 2}=\rho_{2} c_{2} V_{2} \frac{T_{i}^{n+1}-T_{i}^{n}}{\Delta t}
$$

\subsection{Temperature Distribution at the Fin}

By using equation (7), the equation used to calculate the temperature at the control volume $i=2,3,4, \ldots, m-2, m-1, m$, when $t>0$ can be found. The equation for calculating the temperature at the control volume at $i=2,3,4, \ldots, p-2, p-1$, when $t>0$ is expressed by equation (11): 


\section{International Journal of Applied Sciences and Smart Technologies}

Volume 3, Issue 1, pages 111-124

p-ISSN 2655-8564, e-ISSN 2685-9432

$$
T_{i}^{n+1}=\frac{\Delta t}{\propto_{1} \Delta x^{2}}\left[\left(T_{i-1}^{n}-2 T_{i}^{n}+T_{i+1}^{n}\right)+B i_{1}\left(T_{\infty}-T_{i}^{n}\right)\right]+T_{i}^{n} .
$$

The stability requirements for equation (11) are expressed by equation (12):

$$
\Delta t \leq \frac{\rho_{1} c_{1} \Delta x^{2}}{k_{1}\left(2+B i_{1} \frac{\Delta x A s_{i}}{A_{p}}\right)} .
$$

The equation for calculating the temperature at the control volume at $i=p$ when $t>0$, can be expressed by equation (13):

$$
\begin{gathered}
T_{i}^{n+1}=\frac{\Delta t}{\left(\rho_{1} c_{1} V_{1}+\rho_{2} c_{2} V_{2}\right)}\left[\left(k_{1} A_{p} \frac{T_{i-1}^{n}-T_{i}^{n}}{\Delta x}+k_{2} A_{p} \frac{T_{i+1}^{n}-T_{i}^{n}}{\Delta x}\right)\right. \\
\left.+h A_{s}\left(T_{\infty}-T_{i}^{n}\right)\right]+T_{i}^{n} .
\end{gathered}
$$

The stability requirements for equation (13) are expressed by equation (14):

$$
\Delta t \leq \frac{\left(\rho_{1} c_{1} V_{1}+\rho_{2} c_{2} V_{2}\right)}{\left(\frac{k_{1} A_{p}}{\Delta x}+\frac{k_{2} A_{p}}{\Delta x}+h A s\right)} .
$$

The equation for calculating the temperature at the control volume at $i=p$ when $t>0$, can be expressed by equation (15):

$$
T_{i}^{n+1}=\frac{\Delta t}{\alpha_{2} \Delta x^{2}}\left[\left(T_{i-1}^{n}-2 T_{i}^{n}+T_{i+1}^{n}\right)+B i_{2}\left(T_{\infty}-T_{i}^{n}\right)\right]+T_{i}^{n} .
$$

The stability requirements for Equation (15) are expressed by equation (16):

$$
\Delta t \leq \frac{\rho_{2} c_{2} \Delta x^{2}}{k_{2}\left(2+B i_{2} \frac{\Delta x A s_{i}}{A_{p}}\right)} .
$$

The equation for calculating the temperature at the control volume at $i=m$ when $t>$ 0 , can be expressed by equation (15):

$T_{i}^{n+1}=\frac{\Delta t}{0.5 \alpha_{2} \Delta x^{2}}\left[\left(T_{i-1}^{n}-T_{i}^{n}\right)+B i_{2}\left(T_{\infty}-T_{i}^{n}\right)+\left(B i_{2} \frac{A s}{A_{p}}\left(T_{\infty}-T_{i}^{n}\right)\right)\right]+T_{i}^{n}$.

The stability requirements for Equation (17) are expressed by equation (18):

$$
\Delta t \leq \frac{0.5 \rho_{2} c_{2} \Delta x^{2}}{k_{2}\left(1+B i_{2}+B i_{2} \frac{A s}{A_{p}}\right)} .
$$




\section{International Journal of Applied Sciences and Smart Technologies}

Volume 3, Issue 1, pages 111-124

p-ISSN 2655-8564, e-ISSN 2685-9432

\subsection{Heat flow rate, efficiency and effectiveness}

The amount of actual heat released by the fins in the unsteady state condition can be calculated by equation (19):

$$
q_{\mathrm{act}}^{n}=\sum_{i=1}^{m} h A s_{i}\left(T_{i}^{n}-T_{\infty}\right)
$$

The amount of ideal heat released by the fins can be calculated by equation (20):

$$
q_{\text {ideal }}=\sum_{i=1}^{m} h A s_{i}\left(T_{b}-T_{\infty}\right) \text {. }
$$

The amount of heat released by the bottom of the fin, if the length of the fin is considered zero, can be calculated by equation (21):

$$
q_{\mathrm{nofin}}=\sum_{i=1}^{m} h A_{b}\left(T_{b}-T_{\infty}\right)
$$

The efficiency of the fin at an unsteady state condition can be calculated by equation (22):

$$
\eta^{n}=\frac{q_{\mathrm{act}}^{n}}{q_{\text {ideal }}}=\frac{\sum_{i=1}^{m} h A s_{i}\left(T_{i}^{n}-T_{\infty}\right)}{\sum_{i=1}^{m} h A s_{i}\left(T_{b}-T_{\infty}\right)} .
$$

The effectiveness of the fin at an unsteady state condition can be calculated by equation (23):

$$
\epsilon^{n}=\frac{q_{\mathrm{act}}^{n}}{q_{\mathrm{nofin}}}=\frac{\sum_{i=1}^{m} h A s_{i}\left(T_{i}^{n}-T_{\infty}\right)}{\sum_{i=1}^{m} h A_{b}\left(T_{b}-T_{\infty}\right)} .
$$

\section{Research Methodology}

The search for efficiency and effectiveness is carried out using numerical methods. The numerical method used is the explicit finite difference methods. The selected fin shape is a truncated rectangular pyramid (Figure 1). Fins are composed of two different materials. The properties of the fin material are presented in Table 1. The total fin length is $L$, where $L=10 \mathrm{~cm}$. The length of the fin with material 1 is the same as length $\mathrm{p}$ with material 2 , where $L_{1}=L_{2}=5 \mathrm{~cm}$. The section of the fin at the base of the fin, has $a_{1}$ width and $b_{1}$ height, where $a_{1}=1 \mathrm{~cm}$ and $b_{1}=0.5 \mathrm{~cm}$. The section of the fin at the end of the fin, has $a_{2}$ width and $b_{2}$ height, where $a_{2}=0.5 \mathrm{~cm}$ and $b_{2}=$ $0.25 \mathrm{~cm}$. The sum of the control volume on the fin is $m$, where $m=25$. The distance 


\section{International Journal of Applied Sciences and Smart Technologies}

Volume 3, Issue 1, pages 111-124

p-ISSN 2655-8564, e-ISSN 2685-9432

between the control volume is $\Delta x$, and $\Delta x=0.004167 \mathrm{~cm}$. The time interval is $\Delta t$, where $\Delta t=0.05$ second. The temperature of the fluid around the fin is $T_{\infty}$, where $T_{\infty}=$ $30^{\circ} \mathrm{C}$ The base temperature of the fin remains equal to $T_{b}$, with $T_{b}=100^{\circ} \mathrm{C}$. The initial temperature of the fin is $T_{i}$, where $T_{i}=T_{b}=100^{\circ} \mathrm{C}$. The convection heat transfer coefficient is $h$, where $h=100 \mathrm{~W} / \mathrm{m}^{2} .{ }^{\circ} \mathrm{C}$.

Table 1. Properties of the material

(Y.A. Cengel, Heat Transfer A Practical Approach, pp 868-870, see [8])

\begin{tabular}{cccc}
\hline Material & $\begin{array}{c}\text { Density }(\rho) \\
\left(\mathrm{kg} / \mathrm{m}^{3}\right)\end{array}$ & $\begin{array}{c}\text { Thermal Conductivity }(\mathrm{k}) \\
\left(\mathrm{W} / \mathrm{m}^{\circ}{ }^{\circ} \mathrm{C}\right)\end{array}$ & $\begin{array}{c}\text { Specific Heat }(\mathrm{c}) \\
\left(\mathrm{J} / \mathrm{kg} .{ }^{\circ} \mathrm{C}\right)\end{array}$ \\
\hline Copper $(\mathrm{Cu})$ & 8933 & 401 & 385 \\
Aluminum $(\mathrm{Al})$ & 2702 & 237 & 903 \\
Zinc $(\mathrm{Zn})$ & 7140 & 116 & 389 \\
Nickel $(\mathrm{Ni})$ & 8900 & 90.7 & 444 \\
Iron $(\mathrm{Fe})$ & 7870 & 80.2 & 447 \\
\hline
\end{tabular}

\section{Results and Discussion}

The results of the calculation of temperature distribution, actual heat flow rate, efficiency and effectiveness of fins are presented in Figure 7, Figure 8, Figure 9 and Figure 10. The solution using explicit finite difference methods gives satisfactory results. As long as the stability requirements are met, the results are realistic. The truncated rectangular pyramid shape is an example of the shape of the fin. Thus, in the same way, the use of the explicit finite difference methods can be developed for the calculation of efficiency and effectiveness with other fin shapes.

Figure 7 presents the temperature distribution that occurs in the fins with various variations in the composition of the material. At the boundary of the two materials, the temperature distribution looks broken. The fins with an iron-copper composition were more likely to be broken than those with an iron-nickel composition. The results of the temperature distribution in the unsteady state are influenced by the properties of the material such as mass density, thermal conductivity and specific heat. Figure 8, Figure 9 and Figure 10 present the actual heat flow rate of fin removal, fin efficiency and fin effectiveness. The results of this calculation, it all depends on the temperature distribution that occurs in the fin. 


\section{International Journal of Applied Sciences and Smart Technologies}

Volume 3, Issue 1, pages 111-124

p-ISSN 2655-8564, e-ISSN 2685-9432

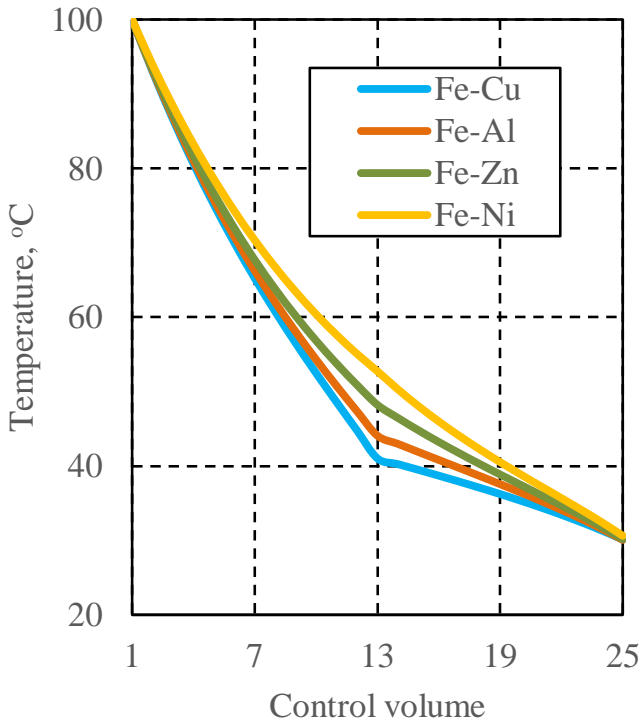

Figure 7. The temperature of the fin at time $\mathrm{t}=100$ seconds

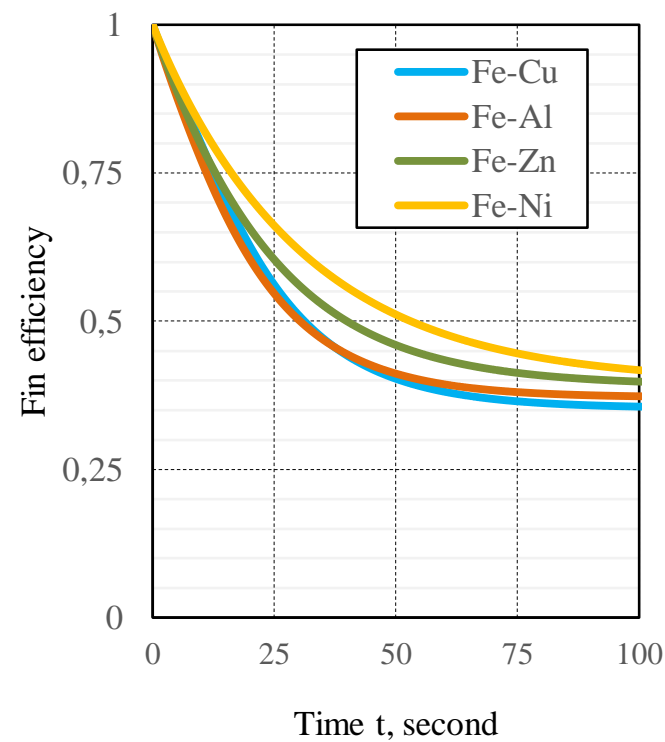

Figure 9. Fin efficiency

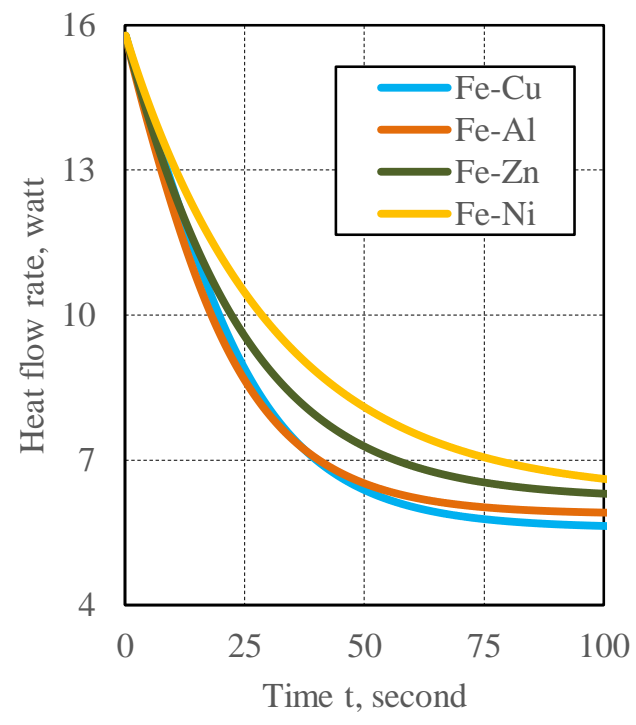

Figure 8. The heat flow rate of the fin

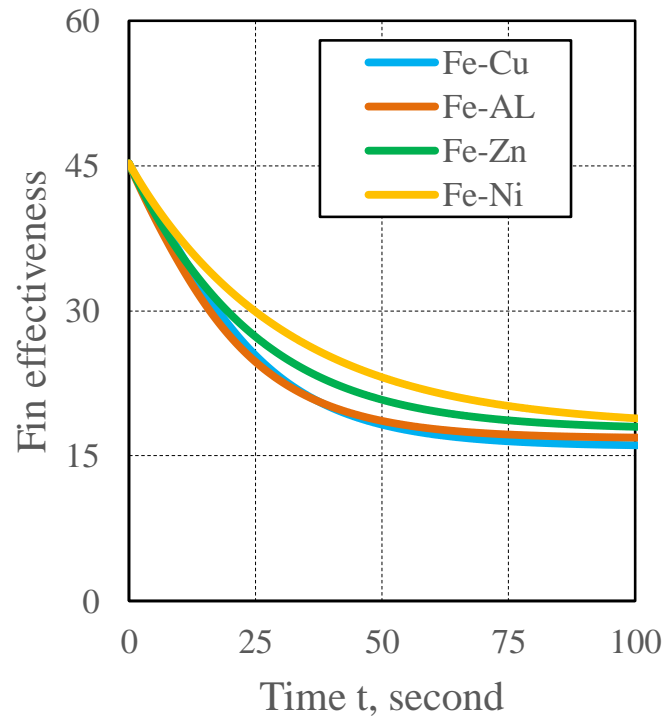

Figure 10. Fin Effectiveness

The use of the explicit finite different methods can also be developed for the case of conduction heat flow which is not only for the one-dimensional case, but also the twodimensional unsteady state case. The two-dimensional case is when the conduction heat 


\section{International Journal of Applied Sciences and Smart Technologies}

Volume 3, Issue 1, pages 111-124

p-ISSN 2655-8564, e-ISSN 2685-9432

flow in the object takes place in two directions: the $\mathrm{x}$ direction and the $\mathrm{y}$ direction. The two-dimensional case occurs for fins with a greater length and width than the thickness of the fin. It can also be developed for the three-dimensional case, with three-directions of conduction heat flow: $\mathrm{x}, \mathrm{y}$, and $\mathrm{z}$ directions.

The fin object discussed in this issue is for fins which are composed of two different materials. If the fins are composed of three or more different fin materials, the use of the explicit finite difference methods can also be used. In this case, the fin material used does not change with changes in temperature. The use the explicit finite difference methods can also be used for fins with temperature changing material properties. Material properties that change due to temperature, such as density, specific heat and thermal conductivity of the fin material.

\section{Conclusion}

As long as the stability requirements are met explicit finite difference methods can be used well to calculate the efficiency and effectiveness of fins in the unsteady state condition. The use of the explicit finite difference methods can be developed for various other fin shapes, which are composed of two or more different materials, the timechanging convection heat transfer coefficient value, and the temperature-changing properties of the fin material.

\section{Acknowledgements}

This research was conducted at Sanata Dharma University. The authors thank Sanata Dharma University for supporting this research.

\section{References}

[1] A.W. Vidjabhakti, P.K. Purwadi, S. Mungkasi, "Efficiency and effectiveness of a fin having pentagonal cross section dependent on the one dimensional position", Proceedings of the 1st International Conference on Science and Technology for an Internet of Things, Yogyakarta, Indonesia, 20 October 2018, doi:10.4108/eai.19-102018.2282540. 


\section{International Journal of Applied Sciences and Smart Technologies}

Volume 3, Issue 1, pages 111-124

p-ISSN 2655-8564, e-ISSN 2685-9432

[2] K.S. Ginting, P.K, Purwadi, S. Mungkasi, "Efficiency and effectiveness of a fin having capsule shaped cross section dependent on the one dimensional position”, Proceedings of the 1st International Conference on Science and Technology for an Internet of Things, Yogyakarta, Indonesia, 20 October 2018, doi:10.4108/eai.19-102018.2282543.

[3] P.K. Purwadi and Bramantyo Yudha Pratama, "Efficiency and effectiveness of a truncated cone-shaped fin consisting of two different materials in the steady-state", AIP Conference Proceedings 2202, 020091 (2019), doi:10.1063/1.5141704.

[4] P.K. Purwadi and Michael Seen, "Efficiency and effectiveness of a fin having the capsule-shaped cross section in the unsteady state", Cite as: AIP Conference Proceedings 2202, 020092 (2019), doi:10.1063/1.5141705.

[5] P.K. Purwadi and Michael Seen, "The efficiency and effectiveness of fins made from two different materials in unsteady-state", Journal of Physics: Conference Series, Volume 1511, International Conference on Science Education and Technology (ICOSETH) 2019, 23 November 2019, Surakarta, Indonesia, doi:10.1088/1742-6596/1511/1/012082.

[6] P.K. Purwadi, Yunus Angga Vantosa, Sudi Mungkasi, "Efficiency and effectiveness of a rotation-shaped fin having the cross-section area dependent on the one dimensional position", Proceedings of the 1st International Conference on Science and Technology for an Internet of Things, Yogyakarta, Indonesia, 20 October 2018, doi:10.4108/eai.20-9-2019.2292097.

[7] T.D. Nugroho and P.K. Purwadi, "Fins effectiveness and efficiency with position function of rhombus sectional area in unsteady condition", AIP Conference Proceedings 1788, 030034 (2017), doi:10.1063/1.4968287.

[8] Y.A. Çengel, Heat Transfer: A Practical Approach (University of Nevada, Reno: The McGraw-Hill Companies, Inc., United States of America, 2008), pp. 163-164. 